\title{
Spontaneous pneumothorax complicating Legionnaires' disease
}

\author{
A. BALI \\ M.R.C.P. (U.K.)
}

\author{
A. A. Pierry \\ M.R.C.P.I.
}

\author{
A. BERNSTEIN \\ F.R.C.P.
}

Department of Thoracic Medicine, Hope and Ladywell Hospitals (University of Manchester School of Medicine) Salford, Lancs.

\section{Summary}

Spontaneous pneumothorax is a known but rare complication of pneumonia in adults. A case is described of Legionnaires' disease complicated by spontaneous hydropneumothorax. So far as is known such an association has not been reported previously.

\section{Introduction}

Pneumothorax as a complication of pneumonia is more likely to occur with those infections associated with cavitation and abscess formation. Presumably rupture of a pneumatocele or abscess into the pleural space is the mechanism of production of the pneumothorax. Organisms most commonly associated with this condition include Mycobacterium tuberculosis (Meyerson, 1948) and Staphylococcus aureus (Mills and Bruce, 1965).

\section{Case report}

A 39-year-old previously fit British male developed malaise, rigors, dry cough, vomiting and watery diarrhoea on the sixth day of his holiday in southern Portugal. The vomiting and diarrhoea subsided after 3 days but the cough persisted and he began to produce mucopurulent sputum. One week later he returned to England and despite therapy with ampicillin he failed to improve. On the tenth day of his illness he developed right-sided pleuritic chest pain and became acutely dyspnoeic. The dyspnoea increased in severity until he was admitted to hospital on the fourteenth day of his illness.

On initial examination his temperature was $37.6^{\circ} \mathrm{C}$, the respiratory rate was $28 / \mathrm{min}$, pulse rate $100 / \mathrm{min}$ and the BP $120 / 80 \mathrm{mmHg}$. Chest expansion was diminished on the right side with dullness to percussion at the right base and absent breath sounds throughout the right side of the chest. There were no other abnormal findings. Initial chest X-ray showed a right-sided hydropneumothorax (Fig. 1).

\section{Laboratory data}

$\mathrm{Hb}$, blood urea and serum electrolytes were normal; white cell count was $23 \times 10^{9} / 1,88 \stackrel{3}{\%}$ polymorphs; ESR $109 \mathrm{~mm} / \mathrm{hr}$; Gram stain of sputum showed polymorphs only and no organism were grown on routine culture; viral serology and mycoplasma fixation test were negative; the diag nosis of Legionnaires' disease was confirmed by indirect fluorescent antibody titres of 1:512 (IgG) and $1: 2049$ (IgM).

Treatment with erythromycin $1 \mathrm{~g} / 6 \mathrm{hr}$ was started at admission, but his subsequent clinic course was unsatisfactory with persisting pyrex and failure of pulmonary re-expansion despitg continuous intercostal drainage to under water

Two weeks after admission a right upper lobec tomy and decortication were carried out

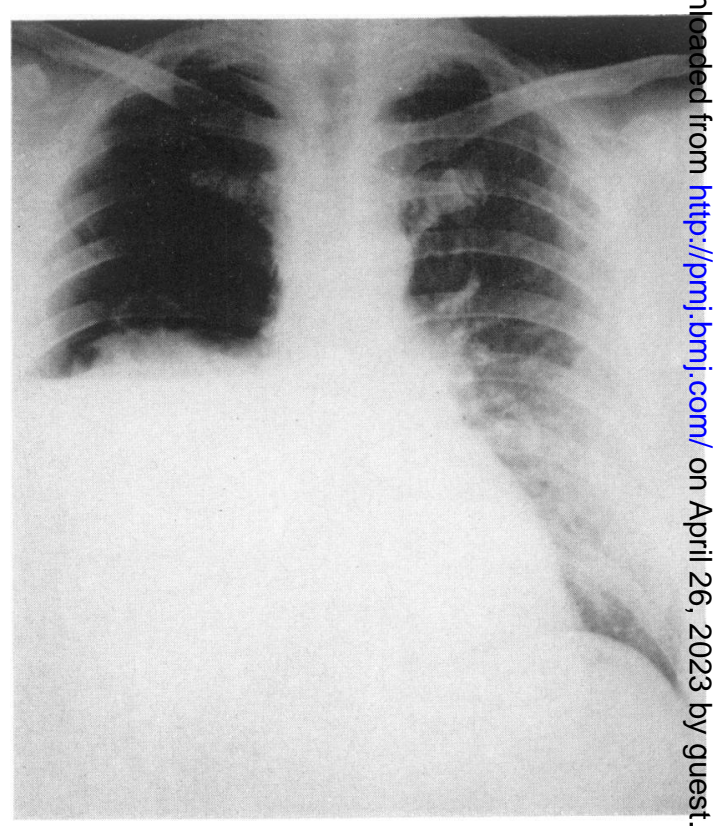

FIG. 1. Initial shest $\mathrm{X}$-ray showing a right-sided hydr pneumothorax.

0032-5473/81/1000-0656 $\$ 02.00$ (C) 1981 The Fellowship of Postgraduate Medicine 
erythromycin was continued for a total of 6 weeks. The postoperative course was uneventful, the pyrexia subsided and the patient was discharged. He has subsequently returned to work. Chest X-ray taken one month later is shown in Fig. 2.

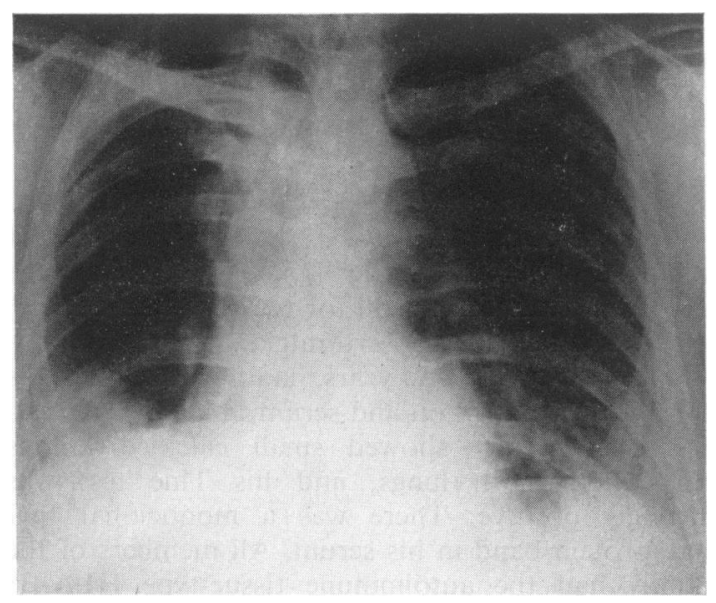

Fig. 2. Chest X-ray of the patient one month after discharge.

\section{Discussion}

Tuberculosis was the commonest infection associated with pneumothorax before the advent of antituberculous chemotherapy (Meyerson, 1948). The pneumonia now most frequently associated with pneumothorax is that due to $S$. aureus (Mills and Bruce, 1965). Organisms more rarely involved include Klebsiella (Pierce, 1974), Pseudomonas aeruginosa and Histoplasma capsulatum (Mills and Bruce, 1965).

Legionnaires' disease is being increasingly recognized as a cause of severe pneumonia. Over 500 cases have been reported in England since 1977 Communicable Diseases Surveillance Centre, Public Health Laboratory Service). Of these patients, about $25 \%$ had been abroad, mainly to Spain and the Balearic Islands and a few to Portugal. The remaining infections were acquired within the United Kingdom.
Infection with Legionella pneumophila causes a wide spectrum of illness from sub-clinical to severe and fatal disease. The complications include encephalopathy, acute renal failure (Tsai et al., 1979), aplastic anaemia (Hajiroussou and Joshi, 1980), thrombocytopenia (Gasper, Farndon and Davis, 1978) and disseminated intravascular coagulation (Oldenburg et al., 1979). Pulmonary involvement may be absent (Carrington, 1979) but occurs in the majority of cases and is usually in the form of patchy consolidation (Swartz, 1979). Pleural effusions, although not uncommon, are small and not a prominent feature of Legionnaires' disease (Swartz, 1979). According to early reports, cavitation did not occur (Swartz, 1979) but cases with cavitation have now been reported (Lake et al., 1979). So far as the present authors are aware there have been no cases reported with a large pleural effusion or with spontaneous pneumothorax.

\section{References}

Carrington, C.B. (1979) Pathology of Legionnaires' disease. Annals of Internal Medicine, 90, 496.

Gasper, T.M., Farndon, P.A. \& DaVis, R. (1978) Thrombocytopenia associated with legionnaires' disease. British Medical Journal, 2, 1611.

HAJIROUSSOU, V.J. \& JosHI, R.C. (1980) Hypoplastic anaemia associated with legionnaires' disease. British Medical Journal, 280, 366.

LaKe, K.B., Van Dyke, J.J., Gerberg, E. \& Browne, P.M. (1979) Legionnaires' disease and pulmonary cavitation. Archives of Internal Medicine, 139, 485.

Meyerson, R.M. (1948) Spontaneous pneumothorax; a clinical study of 100 consecutive cases. New England Journal of Medicine, 243, 461

Mills, M. \& BruCe, B.F. (1965) Spontaneous pneumothorax; a series of 400 cases. Annals of Thoracic Surgery, $3,286$.

Oldenburg, D., Carson, J.P., Gundlach, W.J., Ghali, F.I. \& WRIGHT, W.H. (1979) Legionnaires' disease; association with Mycoplasma pneumoniae and disseminated intravascular coagulation. Journal of the American Medical Association, 241, 1269.

Pierce, A.K. (1974) Aerobic Gram-negative bacillary pneumonias. American Review of Respiratory Diseases, $110,647$.

SWARTZ, M.N. (1979) Clinical aspects of Legionnaires' disease. Annals of Internal Medicine, 90, 493.

Tsai, T.F., Finn, D.R., Plikaytis, B.D., McCauley, W. Martin, S.M. \& Fraser, D.W. (1979) Legionnaires' disease: clinical features of the epidemic in Philadelphia. Annals of Internal Medicine, 90, 509. 